\title{
GEOSPATIAL DATABASE FOR STRATA OBJECTS BASED ON LAND ADMINISTRATION DOMAIN MODEL (LADM)
}

\author{
Nurul Natasha Nasorudin, Muhammad Imzan Hassan, Nur Amalina Zulkifli and Alias Abdul Rahman \\ Department of Geoinformation, Faculty of Geoinformation and Real Estate, Universiti Teknologi Malaysia, UTM Skudai 81310, \\ Johor, Malaysia \\ (natashanasorudin@gmail.com, imzan@utm.my, amalina.jc@gmail.com and alias@utm.my)
}

KEYWORDS: LADM, geospatial database, strata objects

\begin{abstract}
:
Recently in our country, the construction of buildings become more complex and it seems that strata objects database becomes more important in registering the real world as people now own and use multilevel of spaces. Furthermore, strata title was increasingly important and need to be well-managed. LADM is a standard model for land administration and it allows integrated 2D and 3D representation of spatial units. LADM also known as ISO 19152. The aim of this paper is to develop a strata objects database using LADM. This paper discusses the current 2D geospatial database and needs for 3D geospatial database in future. This paper also attempts to develop a strata objects database using a standard data model (LADM) and to analyze the developed strata objects database using LADM data model. The current cadastre system in Malaysia includes the strata title is discussed in this paper. The problems in the 2D geospatial database were listed and the needs for 3D geospatial database in future also is discussed. The processes to design a strata objects database are conceptual, logical and physical database design. The strata objects database will allow us to find the information on both non-spatial and spatial strata title information thus shows the location of the strata unit. This development of strata objects database may help to handle the strata title and information.
\end{abstract}

\section{INTRODUCTION}

In developing a place to store all the information of strata, strata objects database seems could give a new approach and a new direction of strata title. The needs for the strata objects database had been clearly mentioned and discussed in the 3rd International Federation of Surveyors (FIG) Workshop which held in Shenzhen, China in October 2012. This idea can provide exact $3 \mathrm{D}$ objects or properties with their boundaries regarding strata title of features and assist the management including the RRRs (right, restriction, responsibility) of strata title. A strata objects database for cadastre should be capable of storing, manipulating, querying, analysis, updating, and supporting the visualization of RRRs of strata title. The legal, institutional and technical aspects of a strata objects database for cadastre provide the framework for its successful development and implementation. Data modelling is one of the elements of a successful strata objects database and needs to be considered seriously. LADM is a model which creates standardized information services in an international context, where LADM enable the land information to be shared between regions, or countries, in order to enable necessary translations.

Malaysia is one of the potential candidates towards LADM based country profile, as proposed in the research of (Zulkifli, 2014). LADM was introduced in Malaysia as standard concepts or vocabulary in the land administration domain. 'MY_' is the prefix for the Malaysian country profile, covering both the spatial and administrative (legal) data modeling. The proposed draft country profile based on the LADM provides a conceptual model for 2D and 3D cadastral situations for the relevant land administration agencies in Malaysia.

This paper is organized as follows: Section 2 describes the previous works related with LADM and the current cadastre system in Malaysia includes the strata title. The development of strata objects database is discussed in Section 3. Joining the non-spatial with spatial information is elaborated in Section 4. Query of hanging properties is explained in Section 5. Finally, conclusion and future work are discussed in Section 6.

\section{PREVIOUS WORKS}

As been mentioned in (Lee, 2007), traditionally the information for cadastre is stored in 2D nature. Obviously, current cadastral information serves the users need. Currently, because of growing interest in using space under and above the surface, it seems that $2 \mathrm{D}$ geospatial database has problems to handle the information. The existing cadastral system in Malaysia serves the community and users around the country by providing the information in $2 \mathrm{D}$, it works reasonably well but limited to certain extent. The 2D geospatial database faces some difficulties and insufficient to describe the legal status of objects as many property objects nowadays are complex and 3D in nature. In order to solve the problems and to overcome the difficulties, the 3D geospatial database becomes more important in registering the real world (Lee, 2007). The 3D geospatial database helps a lot in solving problems in urban life.

Due to the rapid development in our country, various forms of buildings were constructed to ensure that it is in line with the modernization of the country. For example, multilayered buildings and subsurface objects. This modernization also had led to the development and change of pattern in property ownership. More and higher rise building had been built. All of these types of the property offer different strata information on property ownership other than landed property. As the strata building consist two or more levels, the $3 \mathrm{D}$ geospatial database is the most effective way to display the strata information. The 
building of 3D model will link with the 3D geospatial database; hence the searching process will be easier with the present of actual display of the strata building. As stated by (Hassan et al., 2008), the need for a 3D geospatial database for cadastre is increasing in Malaysia in line with the rapid development of our country. In big cities, for example Kuala Lumpur, most of the buildings constructed in a complex way in order to optimize the limited space

There are problems in the use of $2 \mathrm{D}$ such as the display of the strata building structure is not clear. In addition, the $2 \mathrm{D}$ form cannot display the entire lot perfectly. As we know, strata title information was stored in the files and in 2D form. Therefore, the searching and storing processes take time. From a formal discussion and interview session with the relevant authority from 'Pejabat Tanah dan Galian' (PTG) Johor, the strata title information being kept by the PTG in 2D and hard copy form. Each strata title information of a parcel in a building will be store in a grant which is in hardcopy form. This is very inconvenient for the parties need to find the grants. Strata title information storage problems in hardcopy can be reduced by the development of strata objects database.

Meanwhile, to enable 'Jabatan Ukur dan Pemetaan Malaysia' (JUPEM) review the existing plans, the delivery will be made to the JUPEM Office by PTG itself. The process is hard to be done as it in A3 form. This is because it requires lots of space. Recently in JUPEM Johor, they have begun using strata objects database for information storage cadastre survey. The strata objects database development is still new and in an experimental stage. The certified strata plan is stored in the form of $2 \mathrm{D}$. Figure 1 shows the certified strata plan. The certified strata plan represents the certified strata plan in Malaysia only shows the floor plan for each lot in the building.

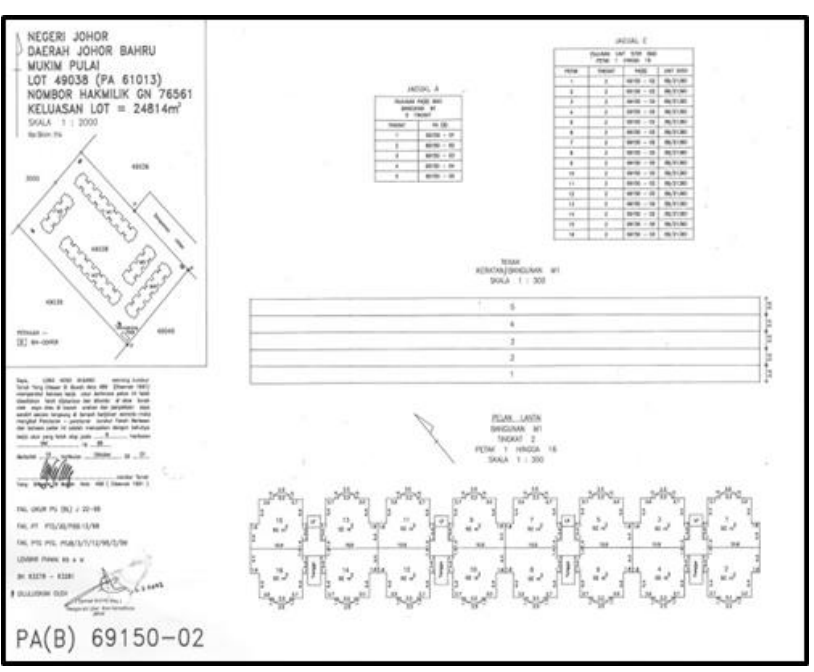

Figure 1. Certified plan provided by JUPEM

It is worth to mention that issues of three-dimensional determination of property rights are becoming more and more important. 3D properties are not something new but they are like other conventional properties. They can be transferred, mortgaged, expropriated, inherited and can be created by cadastral procedures as a subdivision, partition and amalgamation.

3D properties are an extension of the concept of conventional properties, which possess all of the features pertaining to conventional properties, and can be integrated, in the same legal framework as conventional properties. However, 3D properties have more advanced features where they are volumes, parts of spaces, while conventional properties are areas and parts of the earth's surface. 3D properties can occupy different parts of space. They can be subdivided into strata that create separate parcels above or under the original surface parcels.

According to the Strata of Laws Act 1968, even it allow land subdivides into parcel base on the area occupy, but all these still in 2D nature, therefore, it is still doubtful and facing many problems to show the legal rights of the ownership when it comes to a complicated situation cases (Strata of Law Act 1968, 2006). Also, although under National Land code, Act 56 of 1965 air space are permitted, but it is limited to the maximum of 21 years only and there are still a lot of arguments about the surface under different categories of land use. Furthermore, these 3D constructions and infrastructures generally not correspond to each other with the law and legal for each organization, which are legally registered and defined.

As such, the current related land law needs to enhance to suit with the related organization in order for the cadastral survey and mapping system and land registration system can work together without any discrepancy in the process and procedure.

In order to encounter with strata title and information, data modeling is one of the elements in developing a successful 3D strata geospatial database. 3D geospatial database data model supports the users to understand the structure or behavior of the system and has a template that guides them to construct and implement the 3D geospatial database (Mohd Noh, 2012).

According to Oosterom, LADM capable to covers basic geospatial data including those over water and land, and features above and below the surface of the earth (Oosterom, 2012). Hence, LADM seems to be the most suitable standard data model where it is developed corresponding to the cadastral situation in the environment of Malaysian cadastral registration system. LADM is having the capability to handle the strata title registrations which come in $3 \mathrm{D}$ information. The most important in handle strata title registration is the RRR's for each lot in a building.

\section{DEVELOPMENT OF STRATA OBJECTS DATABASE}

It is a process of yielding a detailed and thorough data model of a database. It contains all the needed logical and physical design choice and physical storage parameters that are needed to create a database. For this paper, the construction of the database was based on the Malaysian LADM country profile.

There are three types of database design namely;

i. Conceptual database design

ii. Logical database design

iii. Physical Database design

In the conceptual stage, classes that need to be included in the data model are recognized, together with the attributes and relationships of the classes. The conceptual model is important to determine the parts of the real world which are significant for a particular purpose. The model also needs to have a high 
abstraction level since it is the basis of the conception procedure.

Logical database design was required before the beginning to develop a physical database design and the logical database design grows out of a conceptual database design. Logical database design was the stage we design the master data list. The master data list was important in order for us to set up the tables contain in the strata objects database.

Physical database design was the stage which the tables were developed based on the master data list that has been done. This was the stage where the geodatabase schema was translated into actual geospatial database structures.

\subsection{Conceptual Database Design}

In conceptual database design, the process of transforming conceptual database design which in UML Diagram to format that fits in the GIS software and the DBMS that are used. It is the structure of the database. UML diagram is a good presentation of shows the entities, attributes, and relationship that have in a system. The idea of designing the UML below is based on LADM but still need to be considering which tables need to be included based on the data nature that available.

For this paper, the conceptual design was based on the basic UML diagram of LADM Malaysia Country Profile. Although database development process is based on LADM Malaysia country profile, but not all the tables prepared by LADM were used. LADM itself provide freedom for the user while developing a geospatial database. The UML of the strata objects database based on LADM was shown in Appendix 1.

\subsection{Logical Database Design}

In logical database design, the process of transforming conceptual database design which in UML Diagram to format that fits in the GIS software and the DBMS that are used. It is the structure of the database.

\subsection{Physical Database Design}

This is the stage where the information in the master data list was implemented in the strata objects database (Nasorudin, 2015). The coordinate system of the geospatial database was set in the Cassini-Soldner because of the cadastre system in Malaysia was implementing the coordinate system.

There were two types of database that have been developed based on LADM data model which non-spatial and spatial database. Both of this database contain tables which been developed based on the Malaysia LADM country profile.

\section{JOINING THE NON-SPATIAL WITH SPATIAL INFORMATION}

To complete the strata objects database, the 3D model had been joining to test the ability of the constructed 3D model database which has been developed may achieve the research objectives. The non-spatial database was connected to the spatial database using the UPI for 2D feature while UFI for the 3D feature. After completed processing phase, analysis has been carried out on the constructed 3D model. Several queries were done on the strata objects database. The purpose was to ensure the model and the strata objects database was related to one another.

Besides, it is also to ensure the model and this study gives the organization sufficient information for a better management in strata title. In addition, it aims to test the strata objects database whether it was good enough developed or not.

\subsection{Unified Parcel Identifier (UPI)}

UPI is a unique way of identifying land parcels under the responsibility of the state authorities. It was intended to identify the structural shape and physical characteristics of each parcel of land (lots). Each compartment lot predefined code structure is aligned to facilitate the sharing of information on the ground and help each user make transactions related to land. However, UPI in 2D was not able to display the actual characteristics of strata lot parcels. Figure 2 below shows the code for every state in Malaysia. UPI code for the entire structure, include the state, country, district, sub district, section and lot number. Table 1 below describes the examples of UPI code.

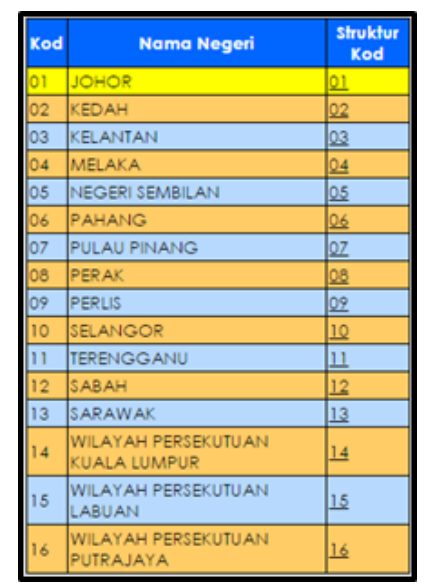

Figure 2. UPI code for each state in Malaysia

\begin{tabular}{lllll}
\hline State & District & Sub District & Section & Lot \\
\hline Johor & Batu Pahat & Bagan & & \\
\hline 01 & 01 & 01 & 000 & 0001234 \\
\hline UPI & $\mathbf{0 1 0 1 0 1 0 0 0 0 0 0 1 2 3 4}$ & & \\
\hline
\end{tabular}

Table 1. Example of UPI code structure

\subsection{Unified Feature Identifier (UFI)}

UFI was necessary to overcome the problems encountered in the management of cadastre. UFI is a continuation coding UPI. In setting UPI for each land (lot), it involves code for the state, district, section and lot number were added up to 16 characters. UFI code setting was done by adding code to the building, and the degree to strata lot. Table 2 below show the criteria for UFI code.

\begin{tabular}{lll}
\hline BORDER & TYPE & CHARACTER \\
\hline Building & Numeric \& Alphabet & 3 \\
\hline Level & Numeric \& Alphabet & 3 \\
\hline Strata Lot & Numeric \& Alphabet & 4 \\
\hline
\end{tabular}

Table 2. UFI criteria codes 


\section{HANGING PROPERTIES}

Hanging properties are two buildings on two different lots and where the bridge that connects them has strata parcels. Hanging properties could not be displayed on the floor plan. Therefore, this property is needed to be view in $3 \mathrm{D}$. In this case, if the bridge is located on a different lot, right of the bridge is located on the land owner if the ownership is not changed or sold. However, if the bridge is located on the road then the road is located on the same strata scheme defined as Common Property. According to the 'Pejabat Tanah dan Galian' (PTG) officer, hanging properties owned by the landowner or developer building. However, strata box on the bridge only is done through the approval by each owner.

For this building (hanging properties), the UFI set slightly similar to an apartment. The difference is where the code used starting with the letter J. The codes for the bridge (hanging properties) are for example the code '002' shows hanging properties are on the second floor. Code for strata box on bridges (hanging properties) shall be determined from the sequence of the first box on the bridges (hanging properties) of the first building 'M01' followed by the next box that connects the two buildings, namely 'M02'.

\subsubsection{Query on Attribute}

\section{Query 1: Owner of a parcel of a hanging property}

One example of query could be done in table MY_BAUnit table, we query suID= "1008400090001234J010020003". The Figure 3 below shows the result of query after MY_BAUnit table is related to MY_Party table

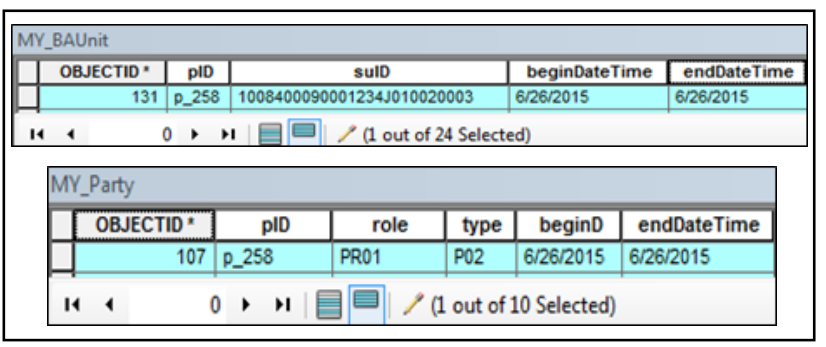

Figure 4. The result after MY_BAUnit table is related MY_Party table

\begin{tabular}{|c|c|c|c|c|c|}
\hline \multicolumn{6}{|l|}{ Oungs: } \\
\hline OQEECTID' & lone & C.10 & Uling zoldress & beginotetim & endogteine \\
\hline 120 & ATHAB BIT & DONOESOO & 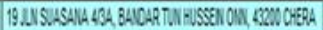 & 6065215 & 665015 \\
\hline
\end{tabular}

Figure 5. The result after MY_BAUnit table is related MY_Party table

Figure 4 above shows all the information regarding the owner of "1008400090001234J010020003" parcel. The owner is 'NUR FATIHAH BINTI AMRAN with the identification number of 920708025900.

Query 2: Number of owner of a strata registration number in a hanging property
A parcel is not restricted to own by an owner, In order to know the number of the owner of a parcel, a query could be done by the strata registration number. For example we query, pID = 'p_257' in MY_Party table.

Figure 5 shows the result of a query by the strata registration number (pID) in MY_Party table. While Figure 6 show the number of the owner who owns a parcel with the strata registration number of $\mathrm{p} \_257$.

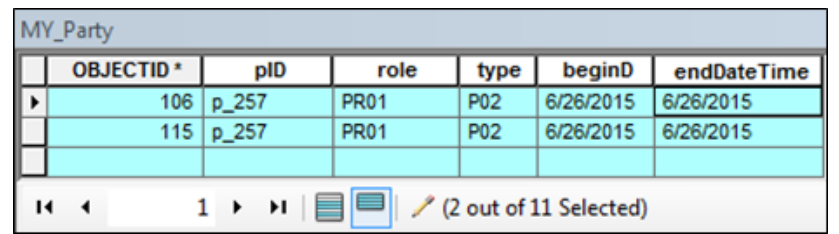

Figure 5. The result of query in MY_Party table

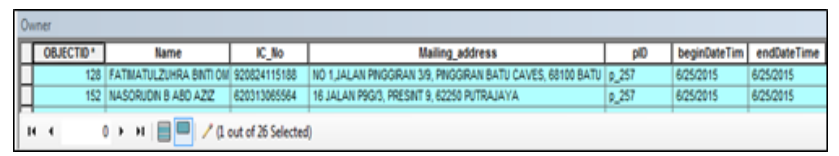

Figure 6. The result in Owner table after related with MY_Party table

\subsubsection{Query on Spatial}

Query 1: Location of a parcel in a hanging property

With a 3D model, we are able to know the location of a parcel of the hanging property. AN example of a query that could be done is to query the UFI (suID) of the parcel. In bridge_parcel table, query suID ="1008400090001234J010020004" OR suID $=" 1008400090001234 \mathrm{~J} 010030014$.

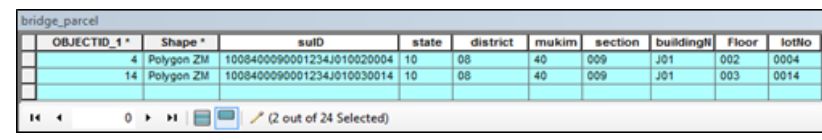

Figure 7. The result of query in bridge_parcel table

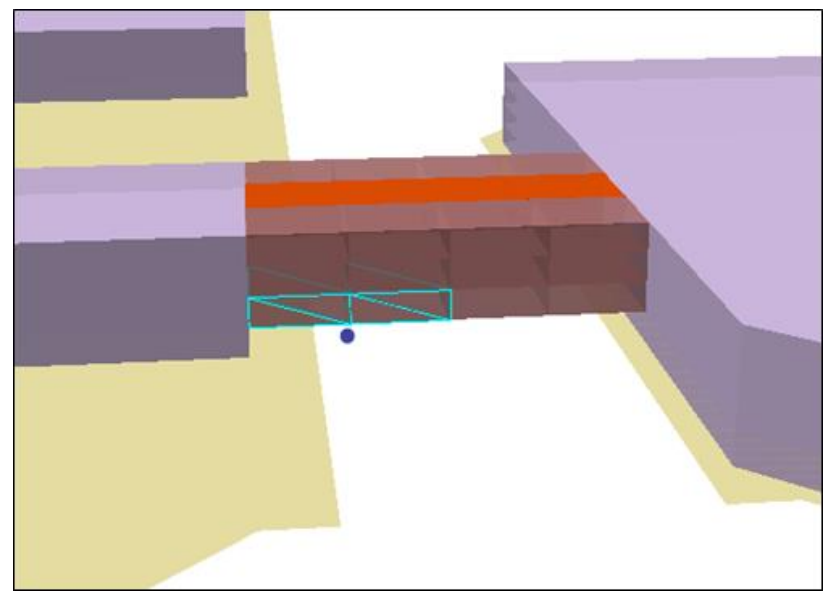

Figure 8 . The location of parcels with suID = "1008400090001234J010020004" and suID = "1008400090001234J010030014"

Figure 7 show the result of the query in bridge_parcel table while Figure 8 shows the location of both parcels. 


\section{Query 2: Location of common property in a hanging property}

With 3D model, we also could know the location of the common property such as foyer in the hanging property. In table bridge_foyer, query suID = "1008400090001234J01004C (3)". $\mathrm{C}(3)$ is the unique code for the foyer. Figure 9 below show the result of the query in bridge_foyer table and Figure 10 show the location of the foyer with UFI (suID) = "“'1008400090001234J01004C(3)". Based on the result, the foyer is located in Level 4.

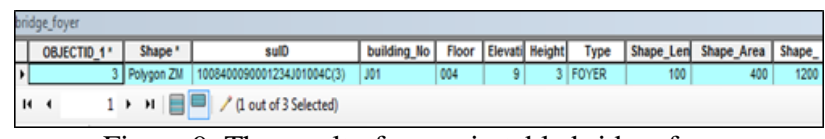

Figure 9. The result of query in table bridge_foyer

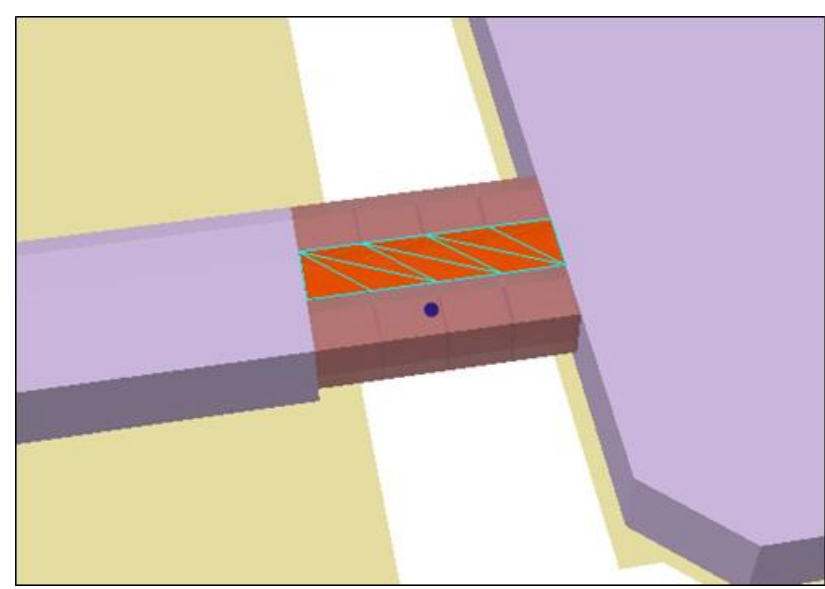

Figure 10. The location of foyer in the bridge (hanging properties)

\section{CONCLUSION}

This paper proposed the development of strata objects database which based on LADM. Following a right procedures or methods in designing the geospatial database was very important as the designing of the database reflects the system and user requirement. The procedures started from conceptual, logical and physical design were all based on the Malaysia LADM country profile. One more steps need to be taken in this study which was to produce the $3 \mathrm{D}$ model of the building in order to complete the development of the strata objects database. In future, using 3D geospatial database, the problems found in the 2D geospatial database can be handled. The 3D geospatial database can give more value added to the current $2 \mathrm{D}$ geospatial database as the needed for 3D strata model is very high due to the rapid development of Malaysia and all the buildings constructed are multi-storey. By implementing this strata objects database in managing the strata title information, it will facilitate and smoothen the process and improve the decision making involve in managing the strata titles in our country.

This research will help the relevant authority like JUPEM and Land Office to store, manage and organize all the geospatial data related to buildings. It is much better to consider the topological factor in the further research of 3D strata geospatial database.

\section{REFERENCES}

Hassan, M. I., 2008. Malaysia 3D Cadastre: Legal and Organizational Aspects. In: Geoinformatics Postgraduate Seminar 2008. Universiti Teknologi Malaysia, Skudai.

Lee, A., T., 2007. Towards Implementations of 3D Strata in Malaysia. Project paper. Bachelor of Geomatics Engineering. Universiti Teknologi Malaysia.

Mohd Noh, N., 2012. Development of Three-Dimensional (3D) Strata Database using ArcGIS Software. Project paper. Bachelor of Geomatics Engineering. Universiti Teknologi Malaysia.

Nasorudin, N. N., 2015. 3D Geospatial Database based on Land Administration Domain Model (LADM). Project paper. Bachelor of Geoinformation. Universiti Teknologi Malaysia.

Oosterom, P.,2012. Summary of the Third International FIG Workshop on 3D Cadastres Developments and Practices. 25-26 October 2012. Shenzhen, China

Strata of Laws Act 1968. 2006. Act 318: The Commissioner of law revision, Malaysia in collaboration with Percetakan Nasional Malaysia Bhd

Zulkifli, N.A., 2014. Adoption of Land Administration Domain Model for Land Administration In Malaysia. MSc Thesis (Geoinformation). Universiti Teknologi Malaysia. 
The International Archives of the Photogrammetry, Remote Sensing and Spatial Information Sciences, Volume XLII-4/W1, 2016 International Conference on Geomatic and Geospatial Technology (GGT) 2016, 3-5 October 2016, Kuala Lumpur, Malaysia

\section{Appendix 1}

UML Diagram of the Strata Objects Database

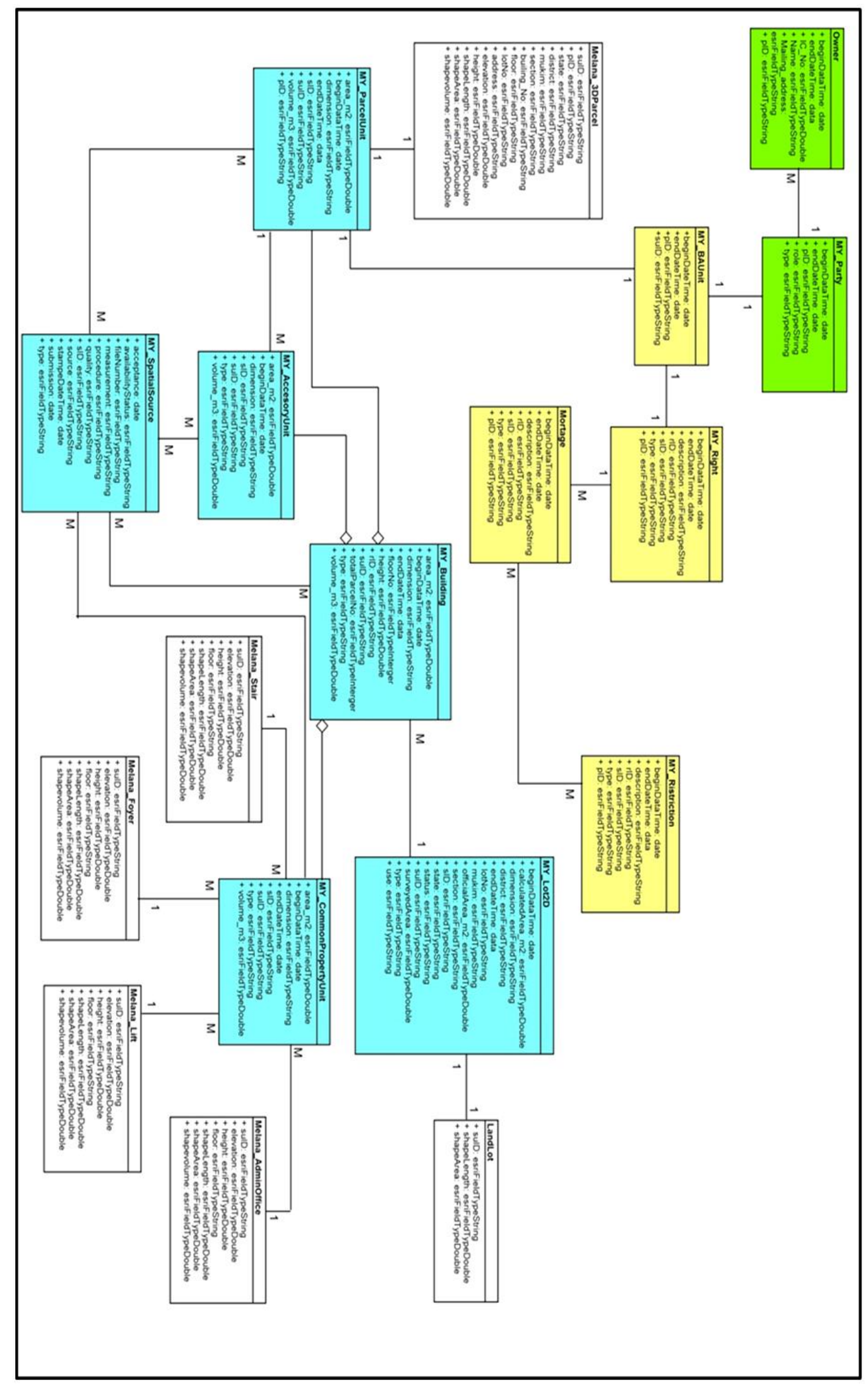

